OPEN

SUBJECT AREAS:

STRUCTURAL GEOLOGY

SEISMOLOGY

TECTONICS

GEODYNAMICS

Received

11 January 2013

Accepted

16 April 2013

Published

7 May 2013

Correspondence and requests for materials should be addressed to

I.K. (katayama@

hiroshima-u.ac.jp)

* Current address:

Department of

Geological Sciences,

Brown University, USA

\title{
Slow earthquakes associated with fault healing on a serpentinized plate interface
}

\author{
Ikuo Katayama', Mutsumi Iwata', Keishi Okazaki * \& Ken-ichi Hirauchi²
}

'Department of Earth and Planetary Systems Science, Hiroshima University, Higashi-Hiroshima 739-8526, Japan, ${ }^{2}$ Department of Interdisciplinary Environment, Kyoto University, Kyoto 606-8501, Japan.

Slow earthquakes that occur at subduction zones are distinct from regular earthquakes in terms of their slip behavior. We consider this difference to relate to localized hydration reactions at the plate interface that influence the frictional properties. The results of laboratory friction experiments indicate that simulated serpentine faults are characterized by a low healing rate and large slip-weakening distance compared with unaltered dry fault patches. These results are consistent with the slip mechanism of slow earthquakes, indicating that a locally serpentinized plate interface could trigger slow earthquakes, assisted by pore pressure build-up, whereas unaltered dry patches that remain strongly coupled are potential sites of regular earthquakes.

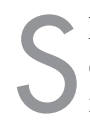
low earthquakes that occur at the subducting plate interface, including low-frequency tremors and slow-slip events, are distinct from regular earthquakes in terms of their slip behavior ${ }^{1}$. The occurrence of these events is attributed to the presence of aqueous fluids on the plate interface, since low seismic-wave velocities and high Poisson's ratios are commonly detected in the source regions ${ }^{2-4}$. Accordingly, it has been widely accepted that fluids make an important contribution to the generation of slow earthquakes due to their role in reducing the effective pressure ${ }^{5,6}$; however, the long characteristic duration and small release of radiation energy during such events cannot be explained by excess pore fluid pressure alone. Consequently, there must be difference in physical mechanism between slow and regular earthquakes ${ }^{7}$. Fluids released from the subducting slab infiltrate into the overlying mantle, and in this case serpentine is expected to form by hydration reactions on the plate interface ${ }^{8}$. Spatial variations in frictional properties on the plate interface can arise from such heterogeneous mineral reactions.

Subduction zone earthquakes occur periodically due to the accumulation of stress/strain at the plate interface. Although a complex combination of mechanical and chemical processes plays a role in earthquake generation, frictional strengthening is likely to make a key contribution to the recovery of fault strength during the period between successive seismic events. Laboratory experiments have demonstrated that friction in stationary contact increases linearly with the logarithm of time $\mathrm{e}^{9-11}$, as follows:

$$
\mu(t)=\mu_{0}+b \log _{10}(t)
$$

where $\mu_{0}$ is the friction at the beginning of stationary contact and $b$ is the healing rate. The time-dependent healing of frictional strength is thought to be a result of thermally activated mechanisms that weld micro-size asperity contacts on the fault surface ${ }^{12}$. However, recent experiments have shown that clay minerals exhibit an extremely low healing rate that may promote aseismic $\mathrm{cree}^{13,14}$. Numerical simulations indicate that the slip-weakening distance, which is the transient distance from the peak friction to steady-state friction, is crucial for generating slow earthquakes, whereby a larger slip-distance is favorable for the generation of slow slip events ${ }^{15,16}$. Hydration at the subducting plate interface results in serpentinization, and such area may differ from dry unaltered patches in terms of healing rate and slip-weakening distance, probably favoring the generation of slow earthquakes. In this study, we test this hypothesis by performing friction experiments of simulated serpentine faults.

\section{Results}

Two types of serpentine were prepared as a starting material: antigorite (a high-temperature polymorph) and lizardite/chrysotile (a low-temperature polymorph $)^{17}$. Quartz and olivine were used separately as dry fault materials for comparison with the serpentine experiments. We carried out a series of slide-hold-slide 

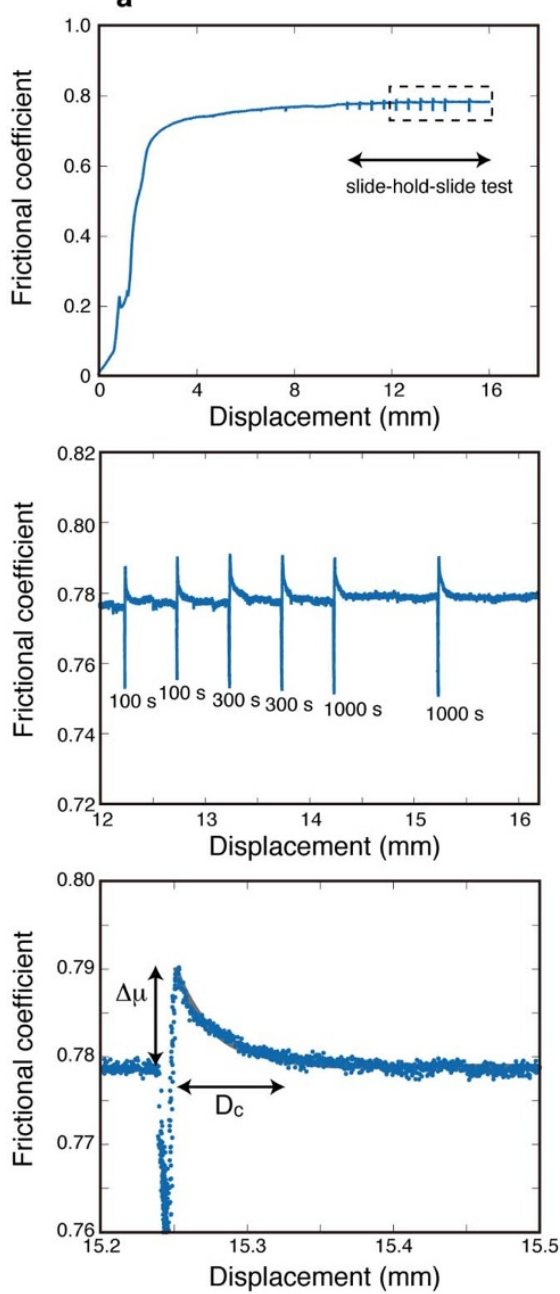

b
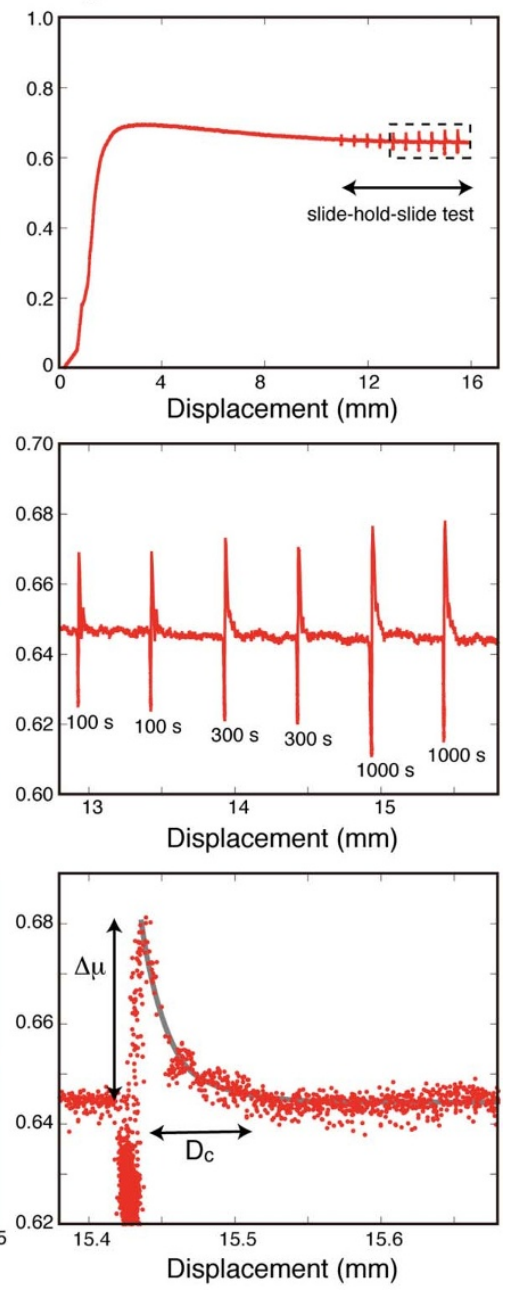

Figure 1 Experimental results of simulated serpentine (a) and quartz (b) gouges as a function of frictional coefficient and displacement. Slide-holdslide tests were performed after $\sim 10 \mathrm{~mm}$ of displacement, and show a peak friction after each holding period. The dashed rectangles in the upper panels indicate the areas shown in the middle panels. Frictional healing $(\Delta \mu)$ is nearly constant for the serpentine, whereas quartz shows a systematic increase during each holding period. Each peak in friction shows a gradual decay to the steady-state friction. The slip-weakening distance $\left(D_{\mathrm{c}}\right)$ was calculated using an exponential decay function (gray line).

friction experiments to examine the time-dependent frictional restrengthening of the simulated fault gouge (Table S1). The experiment results show that the frictional coefficient increases with displacement and attains a steady-state level (Fig. 1). We began the slide-hold-slide tests after $\sim 10 \mathrm{~mm}$ of displacement, to ensure that steady-state frictional behavior had been attained. The axial loading was then interrupted for periods ranging from 10 to $3000 \mathrm{~s}$ at displacement interval of 0.5 or $1.0 \mathrm{~mm}$. We measured the frictional healing effect $(\Delta \mu)$ as the difference between the steady-state friction before each holding period and the peak friction after each holding period (Fig. 1). Figure 2 shows the experimental results of frictional healing $\Delta \mu$ in the simulated fault with different minerals. In the dry gouge materials, frictional healing shows a systematic increase with holding time, which is consistent with previous experiments ${ }^{9-11}$. Frictional healing in the serpentine gouges shows a slight increase with time for a short holding time, whereas peak friction is nearly constant or decreases with a longer holding time of $>1000 \mathrm{~s}$ (Fig. 2). Similar results were obtained for different loading velocities ( 1 and $10 \mu \mathrm{m} / \mathrm{s})$. Under wet conditions, although the frictional coefficient becomes smaller than those under dry conditions (Table S1), the healing properties show a significant difference between the quartz and serpentine gouges.
These data indicate that the healing rate varies with mineralogy in the simulated faults. In particular, for longer holding periods, peak friction tends to be saturated or decrease over time in the serpentine gouges. Similar weak healing has been reported in clay-rich friction experiments, possibly because the platy structure of clay materials enables the contact area to become rapidly saturated ${ }^{13,14}$. Reinen et al. ${ }^{18}$ reported that a peak friction disappeared in the case of a long holding time owing to a shift to the flow-dominated regime. The weak healing in the serpentine gouges of the present study could be a result of effective creeping in the grain wall, since serpentine is known to have a weak creep strength relative to other dry silicates ${ }^{19,20}$.

After each holding period, the peak friction decayed gradually to the steady-state friction when the axial piston was advanced (Fig. 1). The slip-weakening distance $D_{c}$ was calculated using the exponential decay function ${ }^{21}$. The slip-weakening distance tends to have a positive relation with frictional healing (Fig. 3); however, the relation differs between serpentines and dry gouge materials. The healing tests for serpentine gouges show an apparently large slip-weakening distance compared with the quartz and olivine tests, which show a high healing rate and a relatively small slip-weakening distance. The transition between static and dynamic friction is interpreted as the slip necessary to renew the real contacts ${ }^{12}$. The difference in 

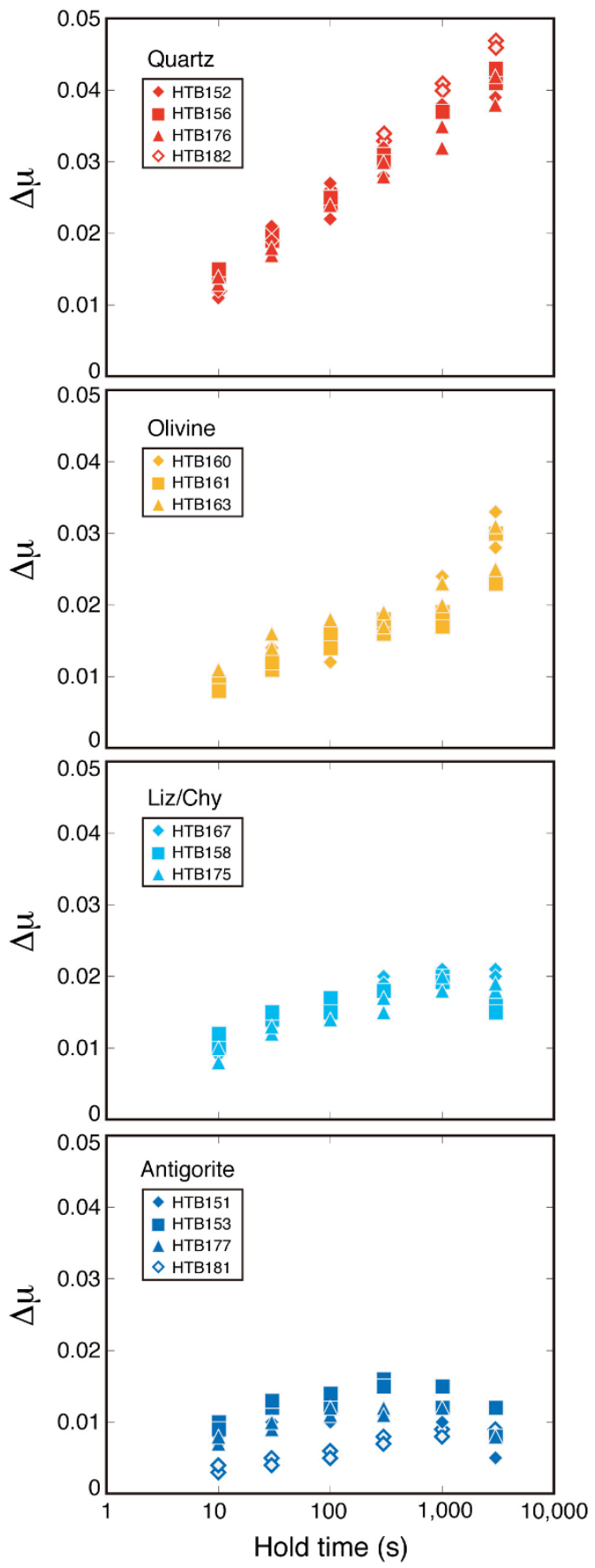

Figure 2 | Frictional healing $(\Delta \mu)$ of four different fault materials. Quartz and olivine show a systematic increase in frictional healing with holding time, whereas the serpentine gouges show a slight increase for short periods followed by nearly constant value or a decrease for long holding time. Liz/ Chy represents a low-temperature serpentine polymorph (lizardite and chrysotile). Note that the filled symbols indicate dry runs, and the open symbols indicate wet runs.

slip-weakening distance between serpentines and dry fault materials may reflect the contrast in creep strength and crystal alignment that influence the asperity contact area, although the physical mechanisms governing this relation are not well understood, as multiple processes operate during transient behavior.

\section{Discussion}

We found that the frictional behavior of simulated faults is markedly different between serpentine and dry silicates, with the former being characterized by weak frictional healing and large slip-weakening distance. These properties are consistent with the characteristics of subduction-related slow earthquakes, which exhibit a small stress drop and a relatively long duration ${ }^{1,7}$. The results of numerical modeling suggest that slow slip events favor a large slip-weakening distance ${ }^{15,16}$. Kuroki et al. ${ }^{22}$ succeeded in producing slow slip events with a large characteristic slip distance in their numerical simulations employing a rate- and state-dependent frictional law. Note that the large slip weakening distance in serpentine gouge help to explain the process of slow earthquakes; however, other frictional behaviors, including velocity dependence and strength heterogeneity, may contribute to the generation of such events at the subducting plate interface.

Given that our experiments were limited to room temperature, caution is needed when applying the present laboratory results regarding frictional properties to natural fault zone. Since the healing is controlled mainly by asperity creep, temperature is likely to affect the healing properties. Laboratory experiments under hydrothermal conditions have shown that the healing rate of quartz gouge is promoted at elevated temperature as a consequence of dissolutionprecipitation assisted creep ${ }^{23}$. Niemeijer et al. ${ }^{24}$ reported that phyllosilicate-bearing gouges tend to prevent healing due to reduced dilation of the fault zone. In addition to serpentine, talc can be produced by metasomatic reactions involving silica-rich fluids, which would result in further weakening of the altered plate interface ${ }^{25,26}$.

Aqueous fluids appear to play a critical role in the generation of slow earthquakes; however, the distinct characteristics of these events, compared with regular earthquakes, point to the contribution of additional factors ${ }^{7}$. Based on our experiment results of frictional healing in serpentines, we propose that materials in the overriding plate at a subduction zone play an important role in the generation of slow earthquakes (Fig. 4). This view is consistent with the heterogeneous fault patch model, in which unstable patches are surrounded by stable regions $\mathrm{s}^{27}$. The upward migration of fluids from the descending slab promotes hydration locally at the plate interface, which becomes weak in terms of frictional coupling. Although unaltered, dry fault patches remain fully coupled and would therefore have the potential to generate regular earthquakes, a hydrated plate interface has the potential to generate slow earthquakes. Such events are located mainly near the Moho, resulting from a build-up of pore pressure ${ }^{28}$, whereas aseismic creep may be dominant at deeper level due to insufficient pore fluid pressure.

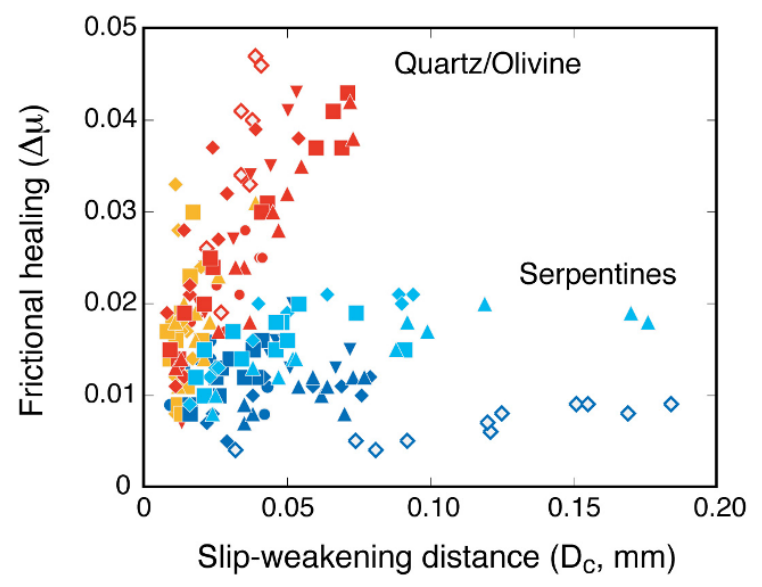

Figure $3 \mid$ Frictional healing $(\Delta \mu)$ versus slip-weakening distance $\left(D_{\mathrm{c}}\right)$ in four different gouge materials (symbols and colors are the same as in Fig. 2). Data are divided into two groups: the serpentine gouges (light and dark blue symbols) show a larger slip-weakening distance and smaller frictional healing than the dry materials (quartz and olivine; red and yellow symbols). 


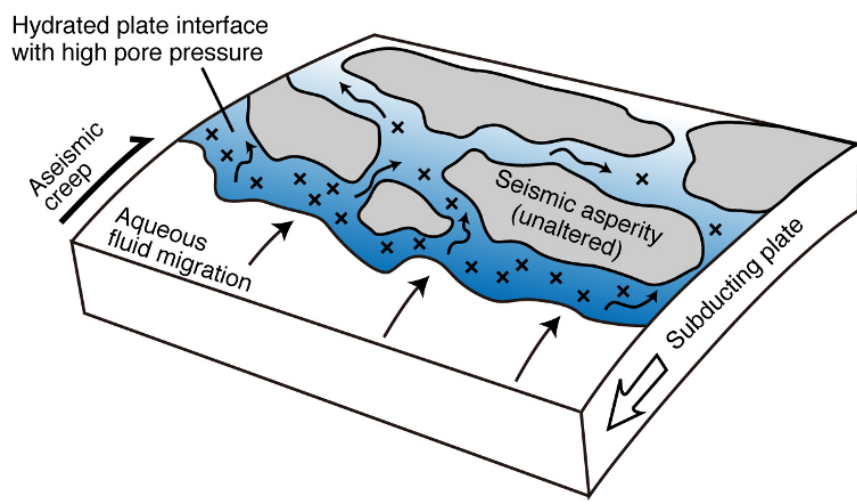

Figure $4 \mid$ Schematic model of the plate interface in a subduction zone. Fluid migration along the plate interface promotes hydration reactions that influence the frictional properties of the interface. The hydrated plate interface could be a potential region of slow earthquakes, assisted by high pore pressure, whereas unaltered dry fault patches remain strongly coupled and have the potential to generate regular earthquakes. The hydrated deeper portions of the interface may deform by aseismic creep due to insufficient pore fluid pressure.

\section{Methods}

The starting materials were crushed using a disk mill to produce a powder with grain size less than $100 \mu \mathrm{m}$, to be used for the friction experiments. All samples were dried at $180^{\circ} \mathrm{C}$ before the experiments to remove any adsorbed water ${ }^{29}$, and X-ray diffraction analysis was performed to confirm that the mineral structure and composition were unaffected by heating.

Friction experiments were performed using a biaxial frictional testing machine at Hiroshima University, $\operatorname{Japan}^{30}$. The powder materials were placed on the simulated fault surface and two side blocks were placed together to produce a double-direct shear configuration (Fig. S1). The thickness of the simulated gouge layer was around $0.7 \mathrm{~mm}$. Normal stress was applied via a hydraulic ram on the side block with $15 \mathrm{MPa}$. Subsequently, shear stress was applied by advancing the central block downward at a constant velocity of $3 \mu \mathrm{m} / \mathrm{s}$. Most of the experiments were conducted under nominally dry conditions at room temperature. Several experiments were also performed under wet environments to assess the effect of water on the healing properties of the fault zone. Axial displacement was corrected using the stiffness of the testing machine $\left(4.4 \times 10^{8} \mathrm{~N} / \mathrm{m}\right)$ and the total displacement was limited to $20 \mathrm{~mm}$ in our assembly. Mechanical data were recorded continuously with a sampling rate of $10 \mathrm{~Hz}$ and the frictional coefficient was calculated from the shear force divided by the normal force, assuming zero cohesion.

1. Ide, S., Beroza, G. C., Shelly, D. R. \& Uchide, T. A scaling law for slow earthquakes. Nature 447, 76-79 (2007).

2. Kodaira, S. et al. High pore fluid pressure may cause silent slip in the Nanka trough. Science 304, 1295-1298 (2004).

3. Shelly, D. R., Beroza, G. C., Ide, S. \& Nakamula, S. Low-frequency earthquakes in Shikoku, Japan and their relationship to episodic tremor and slip. Nature 442, 188-191 (2006).

4. Abers, G. et al. Imaging the source region of Cascadia tremor and intermediatedepth earthquakes. Geology 37, 1119-1122 (2009).

5. Obara, K. Nonvolcanic deep tremor associated with subduction in southwest Japan. Science 296, 1679-1681 (2002).

6. Seno, T. \& Yamasaki, T. Low-frequency tremors, intraslab and interplate earthquakes in Southwest Japan from a viewpoint of slab dehydration. Geophys. Res. Lett. 30, 2171 (2003).

7. Beroza, G. C. \& Ide, S. Slow earthquakes and non-volcanic tremor. Ann. Rev. Earth Planet. Sci. 39, 271-296 (2011).

8. Hyndman, R. D. \& Peacock, S. M. Serpentinization of the forearc mantle. Earth Planet. Sci. Lett. 212, 417-432 (2003).

9. Dieterich, J. H. Time-dependent friction in rocks. J. Geophys. Res. 77, 3690-3697 (1972)

10. Beeler, N. M., Tullis, T. E. \& Weeks, J. D. The roles of time and displacement in the evolution effect in rock friction. Geophys. Res. Lett. 21, 1987-1990 (1994).

11. Marone, $\mathrm{C}$. The effect of loading rate on static friction and the rate of fault healing during the earthquake cycle. Nature 391, 69-72 (1998).
12. Scholz, C. H. The Mechanics of Earthquakes and Faulting (Cambridge Univ. Press, 2002).

13. Carpenter, B. M., Marone, C. \& Saffer, D. M. Weakness of the San Andreas Fault revealed by samples from the active fault zone. Nature Geoscience 4, 251-254 (2011).

14. Tesei, T. et al. Frictional strength and healing behavior of phyllosilicate-rich faults. J. Geophys. Res. 117, B09402 (2012).

15. Shibazaki, B. \& Iio, Y. On the physical mechanism of silent slip events along the deeper part of the seismogenic zone. Geophys. Res. Lett. 30, 1489 (2003).

16. Rubin, A. M. Episodic slow slip events and rate-and-state friction. J. Geophys. Res. 113, B11414 (2008).

17. Evans, B. W., Johannes, W., Oterdoom, H. \& Trommsdorff, V. Stability of chrysotile and antigorite in the serpentinite multisystem. Schweiz. Mineral. Petrogr. Mitt. 56, 79 (1976).

18. Reinen, L. A., Tullis, T. E. \& Weeks, J. D. The frictional behavior of antigorite and lizardite serpentinite: experiments, constitutive models, and implications for natural faults. PAGEOPH 143, 317-358 (1994).

19. Hilairet, N. et al. High-pressure creep of serpentine, interseismic deformation, and initiation of subduction. Science 318, 1910-1913 (2007).

20. Hirauchi, K., Katayama, I., Uehara, S., Miyahara, M. \& Takai, Y. Inhibition of subduction thrust earthquakes by low-temperature plastic flow in serpentine. Earth Planet. Sci. Lett. 295, 349-357 (2010).

21. Mizoguchi, K., Hirose, T., Shimamoto, T. \& Fukuyama, E. Reconstruction of seismic faulting by high-velocity friction experiments: An example of the 1995 Kobe earthquake. Geophys. Res. Lett. 34, L01308 (2007).

22. Kuroki, H., Ito, H. M., Takayama, H. \& Yoshida, A. 3-D Simulation of the occurrence of slow slip events in the Tokai Region with a rate- and statedependent friction law. Bull. Seismol. Soc. Am. 94, 2037-2050 (2004).

23. Nakatani, M. \& Scholz, C. H. Frictional healing of quartz gouge under hydrothermal conditions: 1 . Experimental evidence for solution transfer healing mechanism. J. Geophys. Res. 109, B07201 (2004).

24. Niemeijer, A., Marone, C. \& Elsworth, D. Healing of simulated fault gouges aided by pressure solution: Results from rock analogue experiments. J. Geophys. Res. 113, B04204 (2008).

25. Moore, D. E. \& Lockner, D. A. Frictional strengths of talc-serpentine and talcquartz mixtures. J. Geophys. Res. 116, B01403 (2011).

26. Hirauchi, K., Den Hartog, S. A. M. \& Spiers, C. J. Weakening of the slab-mantle wedge interface induced by metasomatic growth of talc. Geology 41, 75-78 (2012).

27. Ando, R., Nakata, R. \& Hori, T. A slip pulse model with fault heterogeneity for low-frequency earthquakes and tremor along plate interfaces. Geophys. Res. Lett. 37, L10310 (2010).

28. Katayama, I., Terada, T., Okazaki, K. \& Tanikawa, W. Episodic tremor and slow slip potentially linked to permeability contrasts at the Moho. Nature Geoscience 5, 731-734 (2012).

29. Morrow, C. A., Moore, D. E. \& Lockner, D. A. The effect of mineral bond strength and adsorbed water on fault gouge frictional strength. Geophys. Res. Lett. 27, 815-818 (2000).

30. Noda, H. \& Shimamoto, T. Constitutive properties of clayey fault gouge from Hanaore fault zone, southwest Japan. J. Geophys. Res. 114, B04409 (2009).

\section{Acknowledgements}

We thank T. Shimamoto and T. Noda for technical advice, and Y. Umeda for assistance with $\mathrm{X}$-ray analysis. This study was supported by the Japan Society for the Promotion of Science and by a Grant-in-Aid for Science Research on the Innovative Area of Geofluids.

\section{Author contributions}

I.K. planned the project. M.I., I.K. and K.O. conducted experiments and K.H. collected the serpentinite samples. All authors discussed the results.

\section{Additional information}

Supplementary information accompanies this paper at http://www.nature.com/ scientificreports

Competing financial interests: The authors declare no competing financial interests.

License: This work is licensed under a Creative Commons Attribution-NonCommercial-NoDerivs 3.0 Unported License. To view a copy of this license, visit http://creativecommons.org/licenses/by-nc-nd/3.0/

How to cite this article: Katayama, I., Iwata, M., Okazaki, K. \& Hirauchi, K. Slow earthquakes associated with fault healing on a serpentinized plate interface. Sci. Rep. 3, 1784; DOI:10.1038/srep01784 (2013) 